Florida International University FIU Digital Commons

$6-27-2014$

\title{
Mechanism of Superoxide Mediated Regulation of Particle Uptake and Exocytosis by a GPI-anchored Superoxide Dismutase C in Dictyostelium
}

Maria Pulido

mpuli011@fiu.edu

DOI: $10.25148 /$ etd.FI14071177

Follow this and additional works at: https://digitalcommons.fiu.edu/etd

\section{Recommended Citation}

Pulido, Maria, "Mechanism of Superoxide Mediated Regulation of Particle Uptake and Exocytosis by a GPI-anchored Superoxide Dismutase C in Dictyostelium" (2014). FIU Electronic Theses and Dissertations. 1540.

https://digitalcommons.fiu.edu/etd/1540 


\section{FLORIDA INTERNATIONAL UNIVERSITY}

Miami, Florida

\section{MECHANISM OF SUPEROXIDE MEDIATED REGULATION OF PARTICLE} UPTAKE AND EXOCYTOSIS BY A GPI-ANCHORED SUPEROXIDE DISMUTASE

C IN DICTYOSTELIUM

A thesis submitted in partial fulfillment of the

requirements for the degree of

MASTER OF SCIENCE

in

BIOLOGY

by

Maria Pulido

2014 
To: Interim Dean Michael R. Heithaus

College of Arts and Sciences

This thesis, written by Maria Pulido, and entitled Mechanism of Superoxide Mediated Regulation of Particle Uptake and Exocytosis by a GPI-anchored Superoxide Dismutase $\mathrm{C}$ in Dictyostelium, having been approved in respect to style and intellectual content, is referred to you for judgment.

We have read this thesis and recommend that it be approved.

\begin{tabular}{r}
\hline Lidia Kos \\
\hline Alejandro Barbieri \\
Lou W. Kim, Major Professor
\end{tabular}

Date of Defense: June 27, 2014

The thesis of Maria Pulido is approved.

$\begin{array}{r}\begin{array}{r}\text { Interim Dean Michael R. Heithaus } \\ \text { College of Arts and Sciences }\end{array} \\ \hline \begin{array}{r}\text { Dean Lakshmi N. Reddi } \\ \text { University Graduate School }\end{array}\end{array}$

Florida International University, 2014 


\section{DEDICATION}

I dedicate this thesis to my best friend and mother Judith Navarro. Your unconditional love and support has been the cornerstone of my life. Also to my father Carlos Pulido and the rest of my family, thank you for the support you have given me and for making sure I achieve my goals. Finally I would also like to thank all the teachers and professors I have ever had, especially my major advisor Dr. Lou W. Kim. You have all shaped me into who I am today and I could not be more grateful. 


\section{ACKNOWLEDGMENTS}

First and foremost, I would like to thank my major advisor Dr. Lou W. Kim for letting me join his lab and for his advise and guidance during these last few years. Next I would like to thank my committee members, Dr. Lidia Kos and Dr. Alejandro Barbieri for their insightful suggestions. I would like to acknowledge Dr. Marbelys Rodriguez, Boris Castillo, Bohey Kim, Mujataba Sharief, Dr. Tong Sun, Adwait Kabra, Dr. Sushmita Mustafi, Edward Suh, Dr. Erasmo Perera, and Amy Saldana for their technical help and support. Finally, I would like to thank the FIU Teaching Assistantship program for its sponsorship. 


\begin{abstract}
OF THE THESIS
MECHANISM OF SUPEROXIDE MEDIATED REGULATION OF PARTICLE UPTAKE AND EXOCYTOSIS BY A GPI-ANCHORED SUPEROXIDE DISMUTASE
\end{abstract} C IN DICTYOSTELIUM

by

Maria Pulido

Florida International University, 2014

Miami, Florida

Professor Lou W. Kim, Major Professor

Dictyostelium discoideum is a simple model organism that can be used to study endocytic pathways such as phagocytosis and macropinocytosis because of its homology to cells of the mammalian innate immune system, namely macrophages and neutrophils. Consequently, Dictyostelium can also be used to study the process of exocytosis. In our laboratory, we generated Dictyostelium cells lacking superoxide dismutase SodC. Our data suggest that cells that lack SodC are defective in macropinocytosis and exocytosis when compared to wild type cells.

In this study I describe a regulatory mechanism of macropinocytosis by SodC via regulation of RasG, which in turn controls PI3K activation and thus macropinocytosis. Our results show that proper metabolism of superoxide is critical for efficient particle uptake, for the proper trafficking of internalized particles, and a timely exocytosis of fluid uptake in Dictyostelium cells. 


\section{TABLE OF CONTENTS}

CHAPTER

PAGE

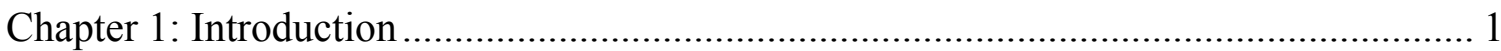

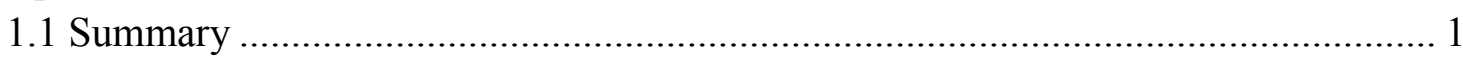

Chapter 2: Literature review .......................................................................................... 2

2.1. sod $^{-}$cells provide a unique opportunity to study the role of ROS in phagocytic cells

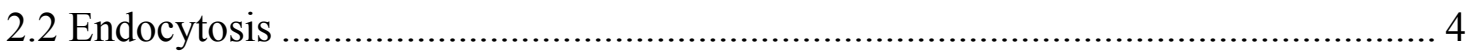

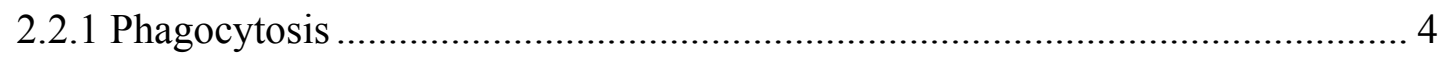

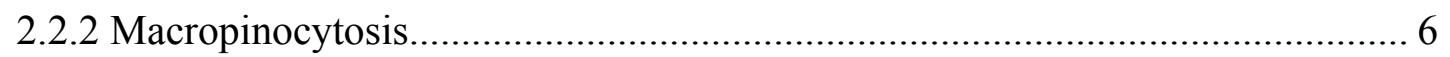

2.3 Inhibitory role of the PI3K inhibitor LY294002 in the process of macropinocytosis

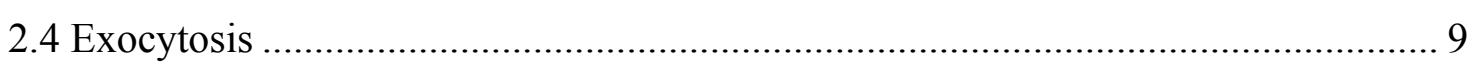

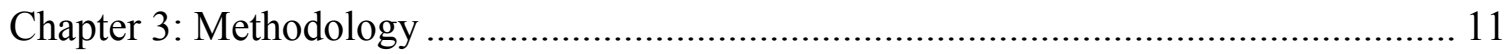

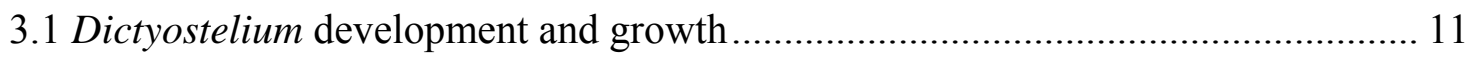

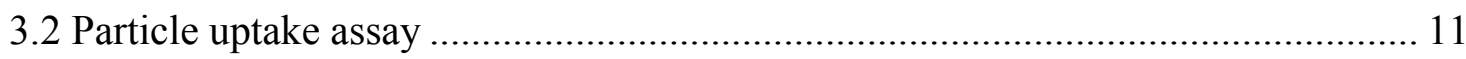

3.3 Quantification of FITC-latex beads internalized.............................................. 12

3.4 Particle uptake assay using a phosphatidylinositol 3-kinase inhibitor.................. 12

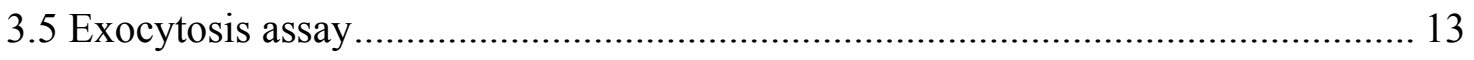

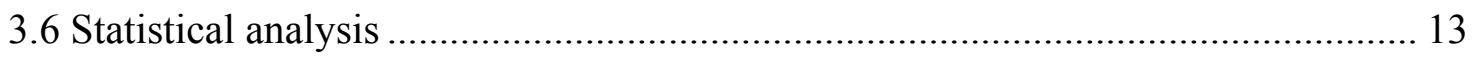

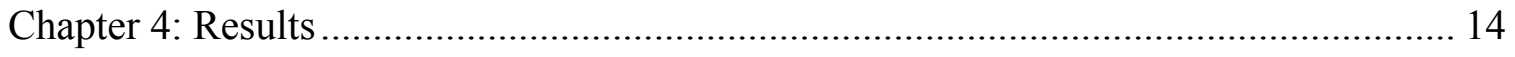

4.1 General aspects of particle uptake in wild type and sod $C^{-}$cells. ......................... 14

4.2 Quantitative analysis of particle uptake in wild type and $s o d C^{-}$cells.................... 15

4.3 sodC $^{-}$cells are defective in macropinocytosis................................................... 16

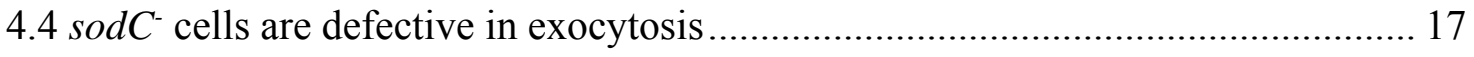

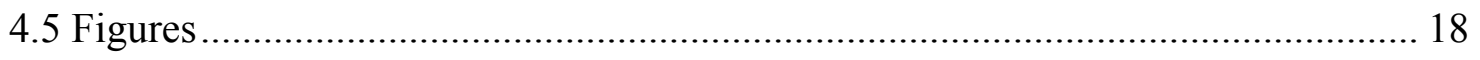

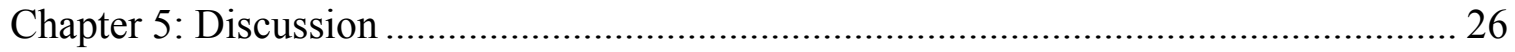

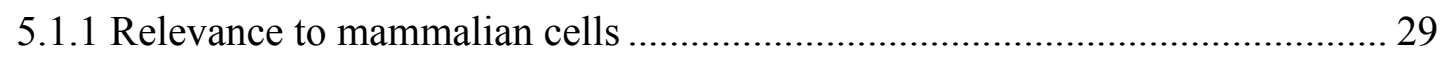

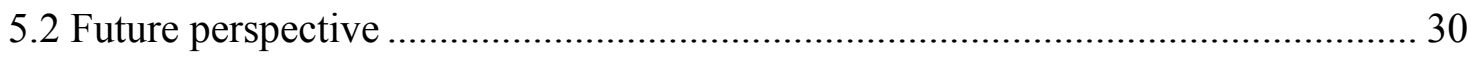

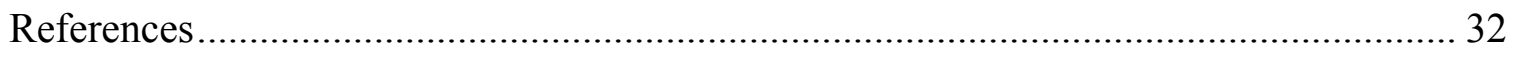




\section{LIST OF FIGURES}

Figure 1: Regulation of phagocytosis and macropinocytosis occurs by two different biochemical pathways......................................................................................... 18

Figure 2: Particle uptake in wild type Dictyostelium discoideum cells ............................. 19

Figure 3: Particle uptake in sodC- Dictyostelium discoideum cells ................................ 20

Figure 4: Particle uptake by wild type and sodC- Dictyostelium cells............................. 21

Figure 5: Particle uptake by wild type and sodC- Dictyostelium cells after addition of the

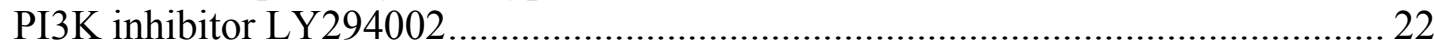

Figure 6: Comparison of particle uptake in wild type and sodC- Dictyostelium cells before and after the addition of the PI3K inhibitor LY294002 ………………….............. 23

Figure 7: Particle uptake in wild type and sodC-Dictyostelium cells after addition of the

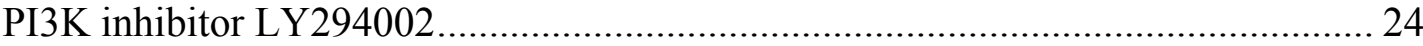

Figure 8: Exocytosis of FITC-dextran in wild type and sodC- Dictyostelium cells.......... 25 


\section{ABBREVIATION AND ACRONYMS}

ABP120

Actin binding protein-120

CLC3 Chloride channel-3

DAG. Diacylglycerol

DAip1 Dictyostelium actin-interacting protein 1 EC-SOD Extracellular superoxide dismutase

F-actin .Filamentous actinl FITC Fluorescein isothiocyanate

GFP Green Fluorescent Protein GTPase. Guanosine trisphosphate phosphohydrolase $\mathrm{IP}_{3}$ Inositol-1,4,5-Triphosphate

IRF-3 Interferon regulatory factor 3

IRF-7 Interferon regulatory factor 3 LmpA

$\mathrm{NADPH}$ Nicotinamide adenine dinucleotide phosphate $\mathrm{NF}_{\mathrm{k}} \mathrm{B}$ nuclear facto- kappaB Nox NADPH oxidase PI3K Phosphoinositide 3 kinase $\mathrm{PI}(3) \mathrm{P}$ Phosphatidylinositol 3-phosphate $\mathrm{PI}(3.4) \mathrm{P}_{2}$ Phosphatidylinositol 3,4-bisphosphate $\mathrm{PI}(3,4,5) \mathrm{P}_{3}$ Phosphatidylinositol 3,4,5-trisphosphate PIK1 .Phosphatidylinositol kinase 1

PIK2. Phosphatidylinositol kinase 2 PIP3 Phosphatidylinositol 3,4,5-trisphosphate 
PKB. Protein kinase B

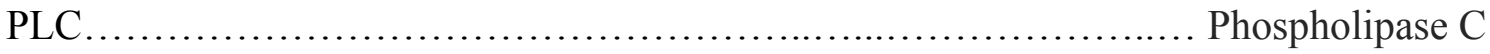

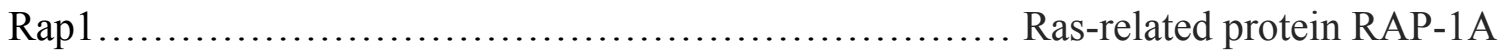

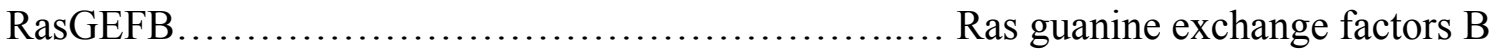

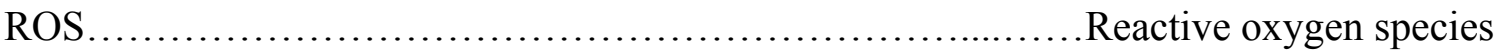

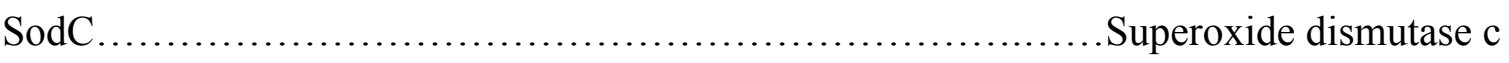




\section{Chapter 1: Introduction}

\subsection{Summary}

The organism Dictyostelium discoideum is a unicellular eukaryote that reproduces by binary fission and undergoes multicellular development in the absence of food (Williams et al., 2006). Dictyostelium discoideum is a "professional" phagocyte and this trait makes it an excellent model to study the molecular mechanisms of chemotaxis and phagocytosis (Maniak, 2002; Annesley and Fisher, 2009). Cells of the human immune system such as neutrophils and macrophages destroy invading microbial pathogens by phagocytosis, which is preceded by chemotaxis. It is not surprising then that some of the proteins involved in chemotactic motility are also involved in phagocytosis, although these proteins are controlled by different upstream receptors and Ras proteins depending on the process (Bozzaro et al., 2008).

The processes of chemotaxis and phagocytosis are not fully understood, not only in their molecular nature but also mechanistically. Furthermore, other processes of particle and fluid uptake such as macropinocytosis and pinocytosis, respectively, are yet starting to be fully comprehended.

In our laboratory we were able to generate Dictyostelium discoideum cells lacking a glycosylphosphatidylinositol (GPI)-anchored superoxide dismutase (SodC). Cells that lack Superoxide Dismutase C, experience oxidative stress as a result of modestly increased intracellular superoxide level ( $\sim 18 \%$ higher compared to wild type), high basal 
RasG activity and defects in chemoattractant sensing, cell polarization and motility (Veeranki et al., 2008).

To identify which and how the processes of particle uptake and exocytosis are affected in Dictyostelium discoideum cells under oxidative stress, we performed a series of assays in which we fed $1 \mu \mathrm{m}$ FITC-latex beads and FITC-dextran to wild type and sodC $C^{-}$Dictyostelium discoideum cells in order to quantify particle uptake and exocytosis, respectively.

\section{Chapter 2: Literature review}

\section{1. sod $^{-}$cells provide a unique opportunity to study the role of ROS in phagocytic cells.}

The release of reactive oxygen species (ROS) occurs normally as a result of oxygen metabolism in the cells. Conversely, the excessive accumulation of reactive oxygen species (ROS) in the cells can prove to be detrimental. The well-studied harmful effects caused by the excessive accumulation of reactive oxygen species (ROS) include: damage to the DNA, lipid peroxidation, oxidation of amino acids and the inactivation of specific enzymes (Brooker, 2011).

One of the functions of ROS that demands further understanding is its role in defense against pathogens in mammalian hosts. A study showed that increased levels of ROS facilitated the signaling to activate interferon regulatory factors three and seven (IRF-3 and IRF-7), and nuclear facto- $\operatorname{kappaB}\left(\mathrm{NF}_{\mathrm{k}} \mathrm{B}\right)$ that result in an antiviral state (West et al., 2011). A more recent study also showed that the production of ROS could 
be responsible for the secretions of interferon type three to control infection by the influenza A virus (Kim et al., 2013).

One of the main reactive oxygen species produced in the cells is superoxide. Normally, cells can defend against superoxide by the family of enzymes of superoxide dismutases. Superoxide dismutases convert superoxide into hydrogen peroxide, which eventually gets converted into oxygen and water. Although the properties of superoxide have been studied in vitro, understanding its role in particle uptake in vivo has proven to be a difficult task because superoxide has a high reactivity and a short half-life. In our laboratory we have previously generated Dictyostelium discoideum cells lacking one of the superoxide dismutases, SodC, in order to understand the role of superoxide in biological processes such as chemotaxis and particle uptake. SodC is a glycosylphosphatidylinositol (GPI)-anchored enzyme that is located in the outer leaflet of the plasma membrane and is involved in the regulation of intracellular level of superoxide in Dictyostelium cells (Veeranki et al., 2008).

Dictyostelium discoideum cells behave like cells of the mammalian innate immune system, namely neutrophils and macrophages, phagocytizing bacteria several fold more than neutrophils (Bozzaro et al. 2008). Dictyostelium discoideum cells lacking SodC exhibit high RasG activity, which was shown to be critical for proper phagocytosis (Chen and Katz, 2000). We thus investigated if sodC cells are defective in particle uptake and other related processes such as macropinocytosis and exocytosis. 


\subsection{Endocytosis}

The term endocytosis refers to all types of plasma membrane internalization, ranging from the formation of small invaginations, $100-200 \mathrm{~nm}$ in diameter, to the formation of large membranous vesicles several micrometers in diameter. Among the category of large membranous vesicles are phagososmes and macropinososmes, formed during phagocytosis and macropinocytosis, respectively (Bohdanowicz and Grinstein, 2013). The main events of endocytosis in wild type Dictyostelium cells are: the formation of an endosome that remains stable in the cell for approximately 1 minute before it starts to lose its coat (consisting of cytoskeletal proteins, including F-actin, and proteins involved in signal transduction) (Maniak et al., 1995; Hacker et al., 1997; Rupper et al., 2001; Peracino et al., 1998; Konzok et al., 1999; Insall et al., 2001; Maniak, 2003); the uncoating of the endosome; acidification of the uncoated endosome via fusion with other vesicles that contain the vacuolar $\mathrm{H}^{+}$ATPase (Clarke et al., 2002); maturation of the acidified endosome from which two processes occur, early recycling and fragmentation (Maniak, 2003); and finally, after subsequent events of the endocytic pathway in wild type Dictyostelium, exocytosis of indigestible particles and fluid (Maniak, 2003).

\subsubsection{Phagocytosis}

Phagocytosis is a receptor-mediated process that occurs when particles bigger than $0.5 \mu \mathrm{m}$ in diameter are recognized by receptors on the surface of professional phagocytes, such as macrophages and neutrophils (Bohdanowicz and Grinstein, 2013).

Phagocytosis involves a number of stages that include recognition and attachment of the cell surface receptors by the binding particles, followed by activation of a signaling 
pathway that leads to the engulfment of the particles, and vesicle trafficking that leads to the formation of phago-lysosomes from phagosomes via a series of fusion and fission reactions (Bohdanowicz and Grinstein, 2013).

In Dictyostelium discoideum cells two classes of receptors have been recognized to be responsible for the binding of particles at the cell surface. One of these receptors binds to the terminal glucose residues in bacteria, while the other class of receptors, the "nonspecific" receptor, is responsible for the binding of particles such as latex beads by hydrophobic interactions (Cardelli, 2001).

There are at least three membrane proteins in Dictyostelium that are responsible for the adhesion of particles to the cell receptors. These proteins are Phg1 (Cornillion et al., 2000), SadA (Fey et al., 2002), and SibA (Cornillion et al., 2006). Among these three, SibA has a cytoplasmic domain that binds to a complex between talin and myosin VII; which are important in the adhesion and engulfment of particles in phagocytosis (Cardelli, 2001; Cosson and Soldatti, 2008).

The binding of particles to the cell receptors causes a signaling pathway that causes F-actin to accumulate below the forming phagocytic cup (Maniak et al., 1995; Cardelli, 2001). In addition to F-actin, ABP120, an actin-crosslinking protein, and coronin also accumulate below the forming phagocytic cup and contribute to its formation and stability (Bretschneider et al., 2009). The pathway that causes F-actin to be spatially and temporally controlled starts with the binding of particles to the cell receptors, which activates phospholipase $\mathrm{C}$ (PLC) through a possible interaction with the $\beta$-subunit of the heterotrimeric G protein. Diacylglycerol, a product of PLC, could 
possibly activate Rap1 and/or RasS while $\mathrm{IP}_{3}$, a second product of PLC, increases cytosolic calcium levels. Both, the activation of Rap1 and/or RasS and the increase of cytososlic calcium level, aid in the regulation of phagocytosis. Furthermore, members of the Rho family such as RacC possibly activate Scar, a protein involved in the polymerization of actin filaments. Additionally, Rab GTPases such as RabB and Rab7 might deliver internal membrane to the newly formed phagocytic cup (Cardelli, 2001).

The formation of a phagocytic cup is followed by a series of maturation steps that eventually lead to the degradation of the ingested particles. During the steps of the maturation process, some proteins are selectively excluded while others are added to the phagosomes. The proteins lining each phagosome give its identity. Once the phagosome starts to fuse with lysososmes, particles ingested are degraded. For example, lysosomal hydrolases such as Cathepsin G and elastase are involved in the killing of S. aureus and C. albicans (Reeves et al., 2002; Cosson and Soldati, 2008); whereas $\beta$-hexosaminidase is involved in the killing of mycobacteria (Koo et al., 2008; Cosson and Soldati, 2008). Another killing mechanism that has been suggested but has been difficult to study in Dictyostelium cells involves the production of reactive oxygen species (ROS) by the NADPH-oxidase. Deficiencies in the ability of NADPH-oxidase to produce ROS lead to inefficient intracellular bacterial killing (Cosson and Soldati, 2008).

\subsubsection{Macropinocytosis}

Macropinocytosis, like phagocytosis, is an actin-dependent but clathrin independent endocytic process. Macropinocytosis differs from phagocytosis in that the macropinosomes are heterogeneous in size, ranging from 0.2 to $5 \mu \mathrm{m}$. Furthermore, 
macropinocytosis is responsible for the uptake of non-specific fluid, solutes, and particles (Mercer and Helenius, 2012). The process of macropinocytosis occurs in several stages that include particle recognition and binding, followed by the activation of an intracellular signaling pathway that leads to F-actin remodeling and plasma membrane protrusions, formation and closure of a vacuole and lastly, macropinosome trafficking (Mercer and Helenius, 2012).

Particle recognition and binding initiate a signaling pathway that triggers a transient change in cell behavior that leads to the actin-dependent formation of membrane protrusions to engulf the attached particles. Depending on the cell type, conditions, and type of receptors involved, the macropinocytic protrusions can take different forms. Among the different forms that macropinocytic protrusions can take are lamellopodial ruffles, circular ruffles, filopodial protrusions, and blebs (Mercer and Helenius, 2012).

Approximately one minute after macropinosome fission from the plasma membrane is completed, the cytoskeletal coat dissociates from the macropinosome and the vacuolar $\mathrm{H}^{+}$ATPase acidifies its lumen (Maniak, 2001).

The formation of late endosomes from early endosomes during macropinocytosis is marked by the effector molecules dynamin and vacuolin, which operate in fission of recycling vesicles and target exocytosis, respectively (Maniak, 2001).

Macropinocytosis and phagocytosis share common protein components such as RasS (Chubb et al., 2000), coronin (Maniak et al., 1995; Cardelli 2001), RasGEFB (Wilkins et al., 2000), Rab7 (Cardelli, 2001), Scar (Seastone et al., 2001), myosin I's, RabD, and DAip1. However, different biochemical pathways regulate macropinocytosis 
and phagocytosis (Cardelli, 2001). For example, the overexpression of RacC or Rap1 in wild type cells and the loss of profiling impair macropinocytosis but stimulate phagocytosis (Seastone et al., 1998; Seastone et al., 1999; Temesvari et al., 2000; Cardelli, 2001). Additionally, deletion of the genes encoding PKB, LmpA, and the genes encoding the P110-like PI 3-kinases PIK1 and PIK2 reduces the rate of macropinocytosis but does not affect phagocytosis (Temesvari et al., 2000; Cardelli 2001). A model representing the common and distinct proteins involved in the processes of phagocytosis and macropinocytosis is depicted in Figure 1.

\subsection{Inhibitory role of the PI3K inhibitor LY294002 in the process of macropinocytosis}

Phosphatidylinositol-3-kinase (PI3K) pertains to a family of enzymes whose multiple functions include intracellular trafficking, motility, differentiation, and proliferation. There are three classes in which the family of phosphoinositol-3-kinase can be identified on the basis of their structure, regulation, and lipid substrate specificity. Tyrosine kinase receptors and G-protein coupled receptors activate Class I of the phosphoinositol-3-kinase. Class I PI3Ks are responsible for the production of Phosphatidylinositol 3-phosphate (PI(3)P), Phosphatidylinositol (3,4)-bisphosphate ( $\left.\mathrm{PI}(3.4) \mathrm{P}_{2}\right)$, and Phosphatidylinositol $(3,4,5)$-trisphosphate $\left(\mathrm{PI}(3,4,5) \mathrm{P}_{3}\right)$.

In wild type Dictyostelium cells, PIP3 patches develop perpendicular to the forming macropinosomes and remain static during the early stages of the process (Veltman et al., 2014). Dictyostelium cells that lack all PI 3-kinases have no PIP3 patches (Hoeller and Kay, 2007). Thus PI 3-kinase inhibitors such as LY294002, inhibit the 
process of macropinocytosis (Veltman et al., 2014). Earlier studies showed that deletion

of the genes encoding the P110-like PI 3-kinases (Class I PI 3-kinases) in Dictyostelium, PIK1 and PIK2, greatly reduced macropinocytosis but did not affect phagocytosis (Temesvari et al., 2000).

\subsection{Exocytosis}

Exocytosis is the process by which a cell guides the contents of vesicles out of the membrane and into the extracellular space. In Dictyostelium cells there are three steps that define the process of exocytosis and these include vesicle trafficking, vesicle docking, and vesicle fusion.

Dictyostelium discoideum cells take in fluid and solutes from the extracellular environment. During the late stages of vesicle trafficking, undigested material accumulates in the late endosomes and is exocytosed (Maniak, 2003). Right before exocytosis, the WASP and SCAR homologue (WASH) derived F-actin, binds and removes the V-ATPase either directly or as part of a larger protein assembly (Carnell et al., 2011) The V-ATPase consists of a membrane channel $\left(\mathrm{V}_{0}\right)$ and a cytoplasmic ATPhydrolyzing proton pump (Jefferies et al., 2008) that is responsible for the acidification of the late endosome; thus by removing the V-ATPase the late endosome gets neutralized.

During normal exocytosis, after the V-ATPase has been removed, actin assembles at several points on the late endosome membrane and exocytosis follows (Clarke et al., 2010). A study showed that fusion of late endosomes with the plasma membrane created the transient formation of a p-80-rich domain at the cell surface and that the 
aforementioned fusion never occurred in sites of the plasma membrane that were undergoing phagocytosis or macropinocytosis, therefore fusion of whole late endocytic compartments is not responsible for membrane delivery to phagocytic or macropinocytic cups or to the cell front (Charette and Cosson, 2006). 


\section{Chapter 3: Methodology}

\subsection{Dictyostelium development and growth}

The JH10 and sodC $C^{-}$cells were grown using D3T medium (14.3g/l Bacto peptone $\# 3,7.15 \mathrm{~g} / 1$ yeast extract, $15.4 \mathrm{~g} / 1$ glucose, $0.48 \mathrm{~g} / 1 \mathrm{KH} 2 \mathrm{PO} 4,0.525 \mathrm{~g} / 1 \mathrm{Na} 2 \mathrm{HPO} 4)$. In addition to D3T medium, JH10 cells were grown with thymidine $(0.5 \mathrm{mg} / \mathrm{ml})$ and $\operatorname{sod} C^{-}$ cells were also grown in thymidine $(0.5 \mathrm{mg} / \mathrm{ml})$ and Blasticidin $(5 \mu \mathrm{g} / \mathrm{ml})$. Both types of cells were grown in shaking cultures at $19^{\circ} \mathrm{C}$ at $150 \mathrm{rpm}$ or in culture flasks at $19^{\circ} \mathrm{C}$ for about 24 hours until they were in log phase. Cell number was monitored using a hemocytometer. Cell number for every experiment performed was between $2 \times 10^{\wedge} 6$ cells $/ \mathrm{ml}$ to $2.4 \times 10^{\wedge} 6 \mathrm{cell} / \mathrm{s} / \mathrm{ml}$.

\subsection{Particle uptake assay}

A total of three million cells of Dictyostelium discoideum growing in the log phase were added to four separate $15 \mathrm{ml}$ centrifuge tubes each. Each $15 \mathrm{ml}$ centrifuge tube was spun down at $2000 \mathrm{rpm}$ for $5 \mathrm{~min}$ at $4^{\circ} \mathrm{C}$. After spinning, cells were resuspended in $1 \mathrm{ml}$ of cold D3T media and fluorescent beads were added to each $15 \mathrm{ml}$ centrifuge tube to a final concentration of 50 beads per cell. Cells and beads were shaken at $150 \mathrm{rpm}$ at room temperature for various times, including a start period consisting of 0-2 minutes (02 minutes accounts for the amount of time the cells were in contact with the beads before spinning and during spinning), $10 \mathrm{~min}, 20 \mathrm{~min}$, and $30 \mathrm{~min}$. After shaking, $1 \times 10^{\wedge} 6$ Dictyostelium discoideum cells were added to $10 \mathrm{ml}$ of cold DB media and washed 4 times in cold DB. After washing, the final pellet was resuspended in $1 \mathrm{ml}$ of DB media at 
room temperature and $500 \mu 1$ of the final $1 \mathrm{ml}$ suspension were placed into a 4 chamber slide and kept at $4^{\circ} \mathrm{C}$ for 10 minutes to allow the cells to settle to the surface of the slide.

\subsection{Quantification of FITC-latex beads internalized}

We used the Leica DM IRB inverted microscope and CoolSNAP-Pro digital camera. We randomly picked 20 Dictyostelium cells and took photos at 100x and at different layers of the z-axis to allow for a 3-D view of Dictyostelium cells. We took approximately 10 pictures in phase contrast every 2 seconds and adjusted the z-axis before every picture to ensure we detected all FITC-beads. We then took approximately twenty images using the GFP filter every 2 seconds and adjusted the z-axis in every picture. We moved through the z-axis approximately $2 \mu \mathrm{m}$ between each picture. We then counted the number of internalized beads in each cell in addition to taking pictures at different z-axis.

\subsection{Particle uptake assay using a phosphatidylinositol 3-kinase inhibitor}

Three million cells of Dictyostelium discoideum growing in the log phase were added to four separate $15 \mathrm{ml}$ centrifuge tubes each. Each $15 \mathrm{ml}$ centrifuge tube was spinned down at $2000 \mathrm{rpm}$ for $5 \mathrm{~min}$ at $4^{\circ} \mathrm{C}$. After spinning, cells were resuspended in $1 \mathrm{ml}$ of cold D3T media and the phosphatidylinositol 3-kinase inhibitor LY294002 (20 $\mu \mathrm{M})$ was added to each $15 \mathrm{ml}$ centrifuge tube and incubated in shaking for $20 \mathrm{~min}$ at room temperature. After the 20 minutes, the assay continued as the particle uptake assay (see above). Quantification of internalized FITC-latex beads was done using the protocol above. 


\subsection{Exocytosis assay}

Total exocytosis of FITC-dextran was measured by following the experimental design by Seastone et al., (2001). Three million cells of Dictyostelium discoideum growing in the $\log$ phase were added to two separate $15 \mathrm{ml}$ centrifuge tubes each. Each $15 \mathrm{ml}$ centrifuge tube was spinned down at $2000 \mathrm{rpm}$ for $5 \mathrm{~min}$ at $4^{\circ} \mathrm{C}$. After spinning, cells were resuspended in $1 \mathrm{ml}$ of cold D3T media and FITC-dextran (relative molecular mass ( $M r) 70,000$, Sigma) was added as the fluid marker at a final concentration of $2 \mathrm{mg} / \mathrm{ml}$ to one of the tubes, the second tube served as control. The two $15 \mathrm{ml}$ centrifuge tubes were then covered in aluminum foil and shaken at 150rpm at room temperature for a period of three hours. After three hours in shaking, cells were washed twice in $1 \mathrm{ml}$ of cold D3T media and resuspended in $7 \mathrm{ml}$ of D3T. Then $1 \mathrm{ml}$ aliquots were collected every twenty minutes, spun down at $2000 \mathrm{rpm}$ for $5 \mathrm{~min}$ at $4^{\circ} \mathrm{C}$ and the supernatant was measured for fluorescence using a spectrofluorimeter using the settings described in Seastone et al., (2001). Before every $1 \mathrm{ml}$ aliquot was taken cells in the $15 \mathrm{ml}$ centrifuge tubes were resuspended to keep cell volume constant during the experiment. To make sure cell number was constant in every $1 \mathrm{ml}$ aliquot, the cell pellet was used to measure protein concentration following a $\mathrm{BCA}^{\mathrm{TM}}$ Protein Assay kit.

\subsection{Statistical analysis}

Statistical analysis of the data was performed using independent t-tests in the SPSS program. The results for the particle uptake assays with and without the addition of the PI3K inhibitor LY294002 were expressed and graphed as mean + standard deviation of the three independently performed sets in both wild type and sodC- ${ }^{-}$Dictyostelium 
discoideum cells, and considered significantly different at $\mathrm{P}<0.05$. The values of percentage fluorescence in the exocytosis assay were calculated measuring the value read in the spectrofluorimeter at $0 \mathrm{~min}$ after the three-hour incubation period as $0 \%$ and then subsequent values obtained were compared and turned into a percentage with respect to the value read at 0 min in both wild type and sodC- Dictyostelium discoideum cells. The percentage fluorescence graphed in the exocytosis assay was an average of the percentages at each time point of three different sets in each cell line.

\section{Chapter 4: Results}

\subsection{General aspects of particle uptake in wild type and sodC $^{-}$cells.}

Wild type and sodC- cells were incubated with the fluorescent (Fluorescein isothiocyanate (FITC)) latex beads up to 30 minutes as indicated in Figure 2 and Figure 3 , and images of randomly chosen twenty cells with internalized latex beads were captured as described in the Methodology. Representative images for each time point were shown in figure 2 and figure 3. The initial time point "Start" realistically represent $1 \sim 2$ minutes because of the unavoidable centrifugation step after mixing the beads with cells. The internalized beads were localized at different depth inside the cell and thus only some of the beads were on the focal plane of each image. The internalized latex beads exhibited noticeable movement, which is reflected in the slightly different positions of beads in the phase contrast and fluorescent images (Fig.2 \& Fig.3) that were taken with a time delay (up to a minute). 
These internalized beads were generally well dispersed throughout the cytoplasm of wild type cells. In contrast, the latex beads in sodC- cells were fewer in number, and surprisingly most of the beads were entrapped in huge vacuoles of $3 \sim 5$ micrometers in diameter (Fig. 3).

The intensity of FITC signal inside the cell is reported to be $\mathrm{pH}$ dependent (Carnell et al., 2011). Consequently, the intensity of FITC-latex bead decreased as the beads entered acidic compartments of the wild type cells (data not shown).

Wild type cells exhibited around ten-fold increase in particle uptake after ten minutes of feeding time (Figure 4) in JH10 cells when compared to the average of internalized particles during the start period. The start period consisted of $0-2$ minutes feeding time. When counting the internalized particles we noticed that the fluorescent beads were dim after ten, twenty, and thirty minutes of feeding time when compared to the start period (data not shown).

\subsection{Quantitative analysis of particle uptake in wild type and sodC cells.}

Over the time course of the assay, wild type cells always demonstrated significantly higher levels of particle uptake compared to sodC cells (Fig.4). The difference in particle uptake between wild type and sodC- cells showed a $\mathrm{P}$ value $<0.05$ at the initial START point and a $\mathrm{P}$ value $<0.01$ at all other time points (Fig.4). Wild type cells internalized 17.5 latex beads per cell during 30 minutes of feeding period, whereas sodC cells internalized $\sim 8$ particles per cell post 20 minutes feeding. No significant increase was observed at 30 minutes of feeding, indicating that sodC- cells not only 
displayed slower rate of particle uptake, but also exhibited severely reduced particle uptaking capacity.

\section{3 sodC- cells are defective in macropinocytosis}

Given that both phagocytosis and macropinocytosis could mediate particle uptake, it would be possible that sodC $C^{-}$cells were defective in either or both of the processes. To determine which is the case, cells were treated for 20 minutes prior to feeding period with PI3K inhibitor, LY294002, which is known to inhibit macropinocytosis, but not phagocytosis of Dictyostelium cells (Veltman et al., 2014). Wild type cells treated with LY294002 displayed significantly decreased ( 40\%) particle uptake over the time course as shown in Figure 5. In contrast, LY294002 treated sodC- cells generally exhibited similar level particle uptake over the assay period (Fig.5 and Fig.7). LY294002 treated sodC- cells seemed to have additional defects in uptaking particles at 20 minutes of feeding, but seemingly normal with additional 10 minutes of feeding period. These results suggest that macropinocytosis, but not phagocytosis, is the most significantly compromised particle uptaking mechanism in sodC $C^{-}$cells.

The internalized beads after treatment with LY were generally well dispersed throughout the cytoplasm just as described in the particle uptake assay without the LY treatment. Similarly, latex beads in sodC $C^{-}$after treatment with LY were still entrapped in huge vacuoles of $3 \sim 5$ micrometers in diameter (Fig. 7). 


\section{4 sodC $^{-}$cells are defective in exocytosis}

Given that macropinocytosis, but not phagocytosis, was the most significantly compromised particle uptaking mechanism in sodC $C^{-}$cells (Fig. 5 and Fig.6), and hence macropinocytosis is the main fluid uptake mechanism in Dictyostelium cells (Hoeller et al., 2013) it would be possible that sodC $C^{-}$cells were also defective in the exocytosisof FITC-dextran. To determine if sodC $C^{-}$cells were defective in exocytosis, we incubated the cells with fluorescent (Fluorescein isothiocyanate (FITC)) dextran (Mr) 70,000 up to 3 hours and measured exocytosis subsequently every twenty minutes for two hours using a spectrofluorimeter, as described in the Methodology.

Wild type cells exhibited $\sim 90 \%$ increase in fluid exocytosis after forty minutes of exocytosis (Fig.8) compared to the initial time pointJH10 cells right after the initial 3 hour incubation period or at 0 minutes after exocytosis (Fig.8). In contrast, sodC ${ }^{-}$cells displayed only $\sim 25 \%$ increase in fluid exocytosis after forty minutes of exocytosis compared to the initial time point (Fig.8).

Over the time course of the assay, wild type cells displayed a steady increase in fluid exocytosis that seemed to reach a plateau after 100 minutes of exocytosis (Fig.8). Conversely, sod $C^{-}$cells did not increase much until they reached 80 minutes of exocytosis, after which fluid exocytosis seemed to increase linearly and $\sim 25 \%$ faster.

At all time points during the assay, sodC $C^{-}$cells displayed a significantly smaller percentage of exocytosed fluid compared to wild type cells. 


\subsection{Figures}

Figure 1
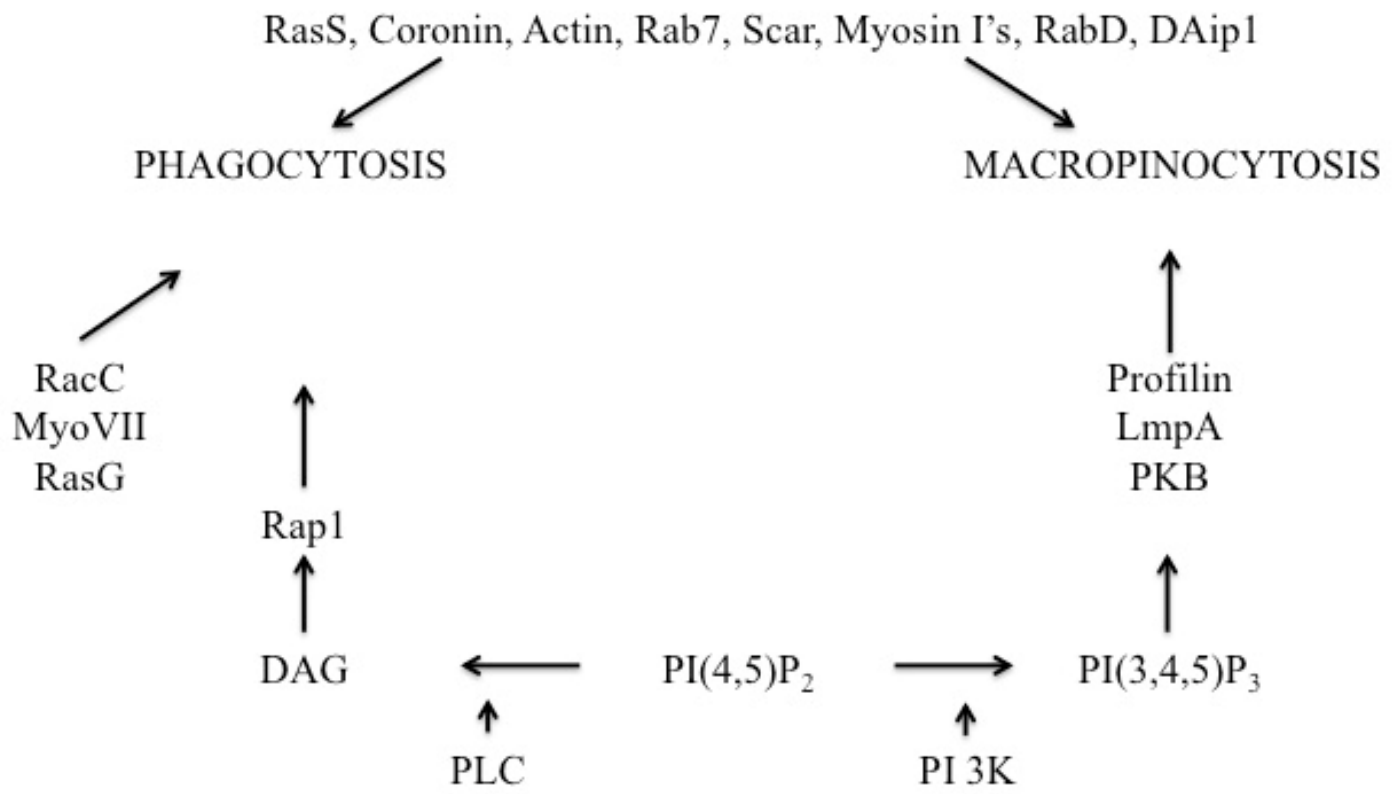

Figure 1: Regulation of phagocytosis and macropinocytosis occurs by two different biochemical pathways

This model shows two possible biochemical pathways by which phagocytosis and macropinocytosis can be regulated. Phagocytosis is initiated when calcium levels increase due to the activation of Rap1. Rap1 is activated by the formation of DAG and $\mathrm{IP}_{3}$. The formation of $\mathrm{DAG}$ and $\mathrm{IP}_{3}$ is catalyzed by PLC. Macropinocytosis is initiated as a result of the accumulation of PIP3 in the nascent macropinosome. PI 3-kinases catalyze the formation of PIP3. RasS, coronin, actin, Rab7, Scar, myosin, RabD, and DAip1 are proteins involved in phagocytosis and macropinocytosis. 


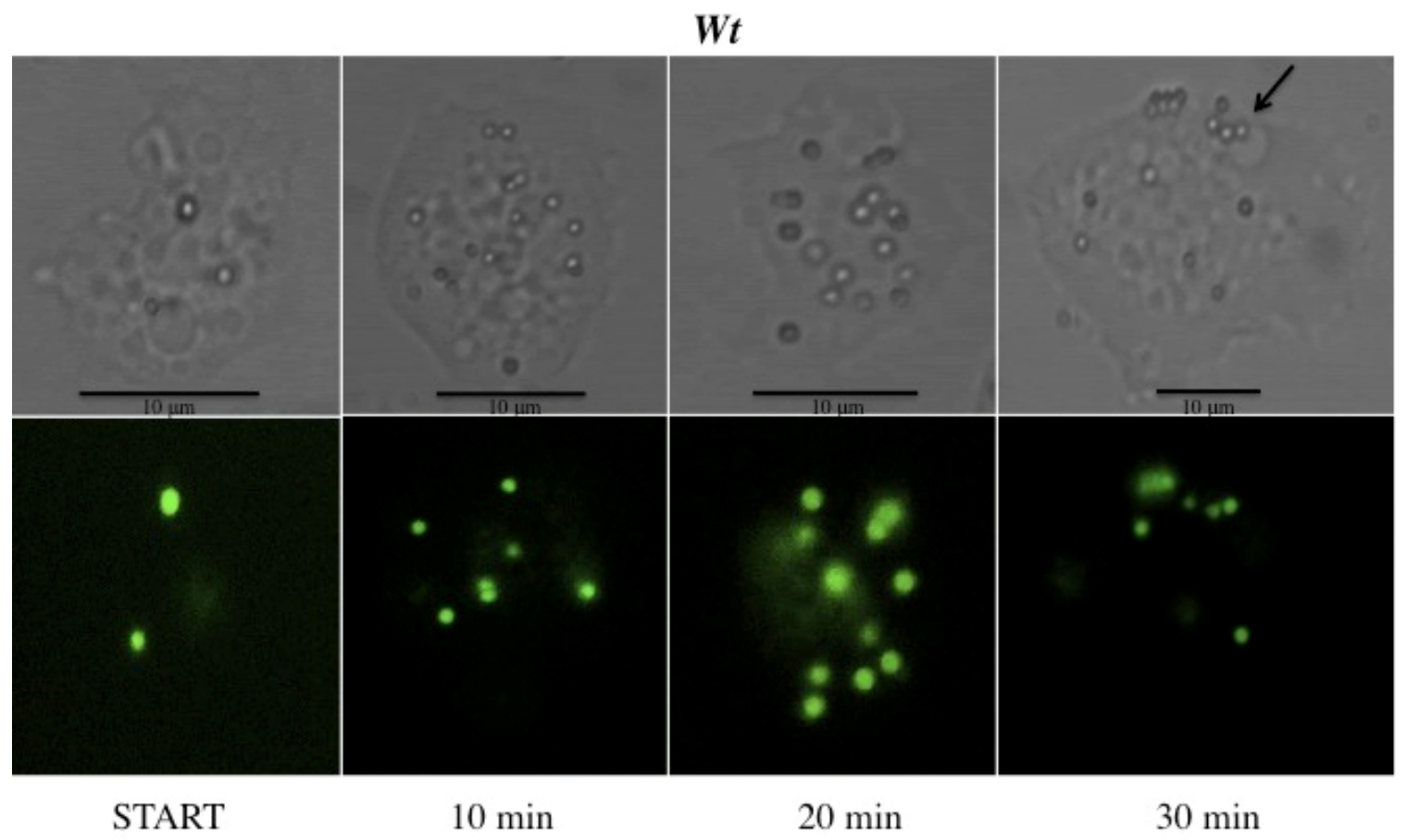

Figure 2: Particle uptake in wild type Dictyostelium discoideum cells

This figure shows an increase in particle uptake as feeding time increases. The start period consists of $1-2$ minutes of feeding FITC-beads to wild type Dictyostelium cells (see Methodology). The top pictures are the most representative phase contrast pictures from randomly picked cells during the particle uptake assay. The bottom pictures are the most representative fluorescent pictures that display the greatest number of FITC-beads in a single z-axis point. Pictures were taken with up to a 1 min difference, hence the movement of particles is accounted for the different positions of the beads in the corresponding phase contrast and fluorescent pictures The arrow in the $30 \mathrm{~min}$ phase contrast picture points at a forming endosome. 


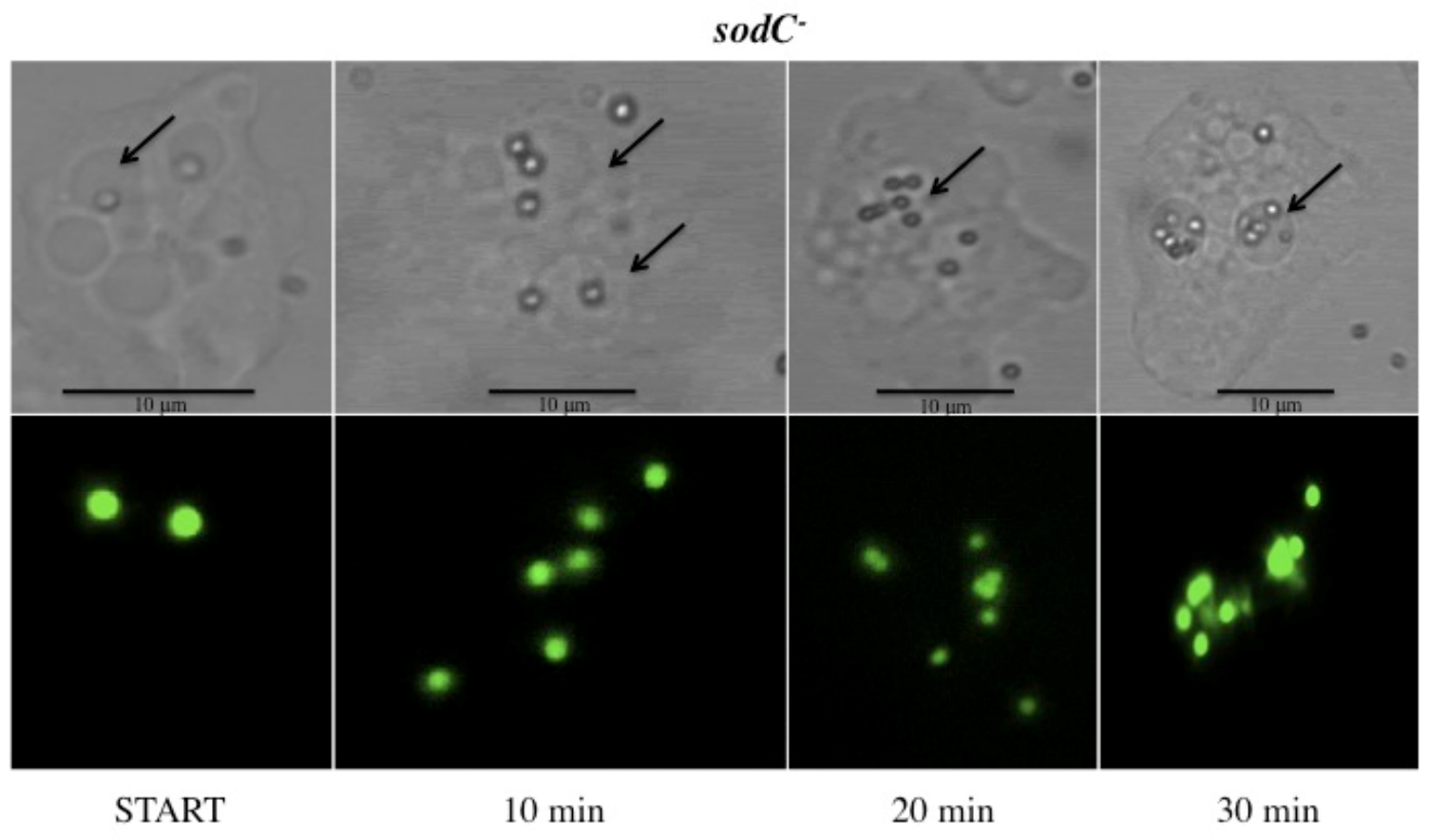

Figure 3: Particle uptake in sodC- Dictyostelium discoideum cells

This figure shows an increase in particle uptake as feeding time increases. The start period consists of $1-2$ minutes of feeding FITC-beads to sodC- Dictyostelium cells (see Methodology). The top pictures are the most representative phase contrast pictures from randomly picked cells during the particle uptake assay. The bottom pictures are the most representative fluorescent pictures that display the greatest number of FITC-beads in a single $\mathrm{z}$-axis point. Pictures were taken with up to a 1 min difference, hence the movement of particles is accounted for the different positions of the beads in the corresponding phase contrast and fluorescent pictures The arrows in the phase contrast pictures point at vacuoles where the FITC-beads are arrested in sodC ${ }^{-}$cells. 
Figure 4

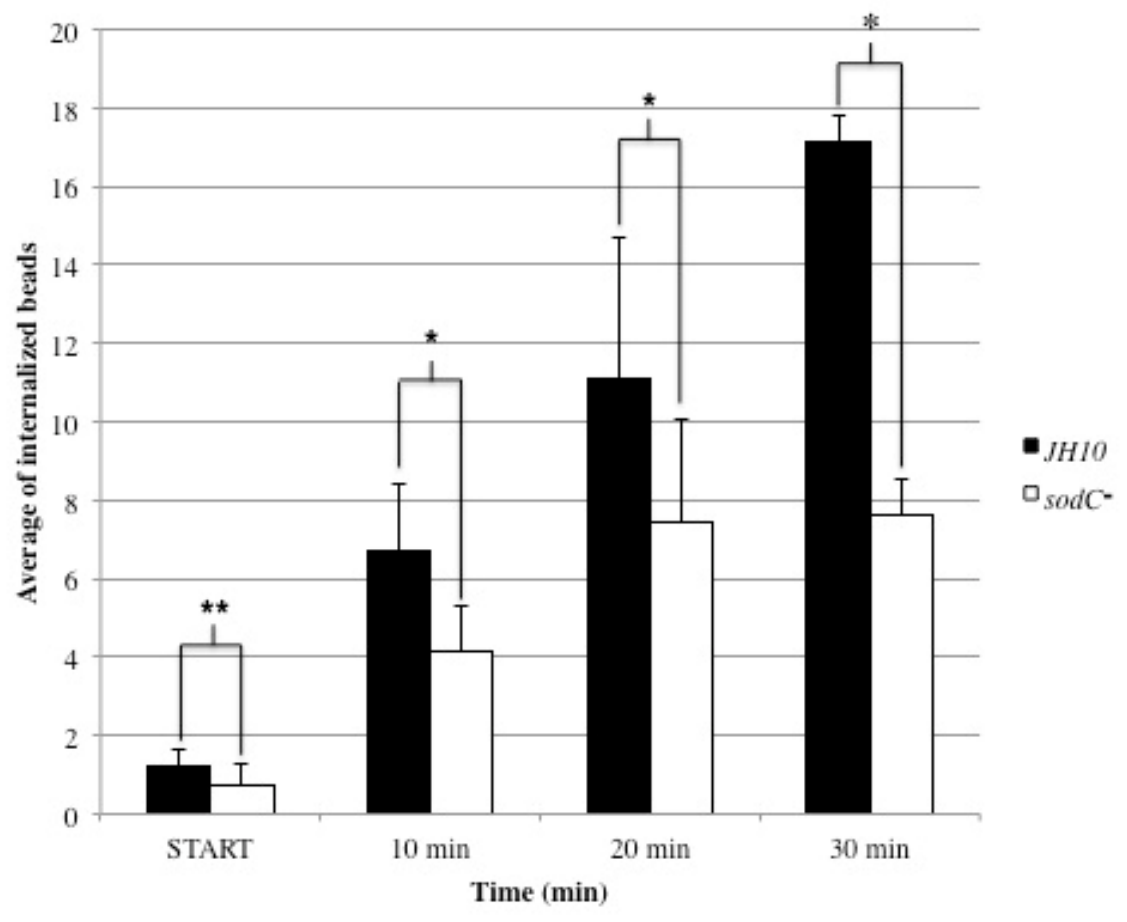

Figure 4: Particle uptake by wild type and sodC- Dictyostelium cells

The average particle uptake of three sets in both wild type and sodC- Dictyostelium cells can be seen though different feeding times. The start period represents $0-2$ minutes of contact between FITC- latex beads and wild type and sodC ${ }^{-}$cells before spinning (see Methodology). The difference in particle uptake between wild type and sodC $C^{-}$cells shows a $\mathrm{P}$ value $<0.05$ at the initial $\mathrm{START}$ point and a $\mathrm{P}$ value $<0.01$ at all other time points. Particle uptake is significantly less in sodC $C^{-}$Dictyostelium cells. $*=\mathrm{P}$ value $<0.01, * *=\mathrm{P}$ value $<0.05$ 
Figure 5

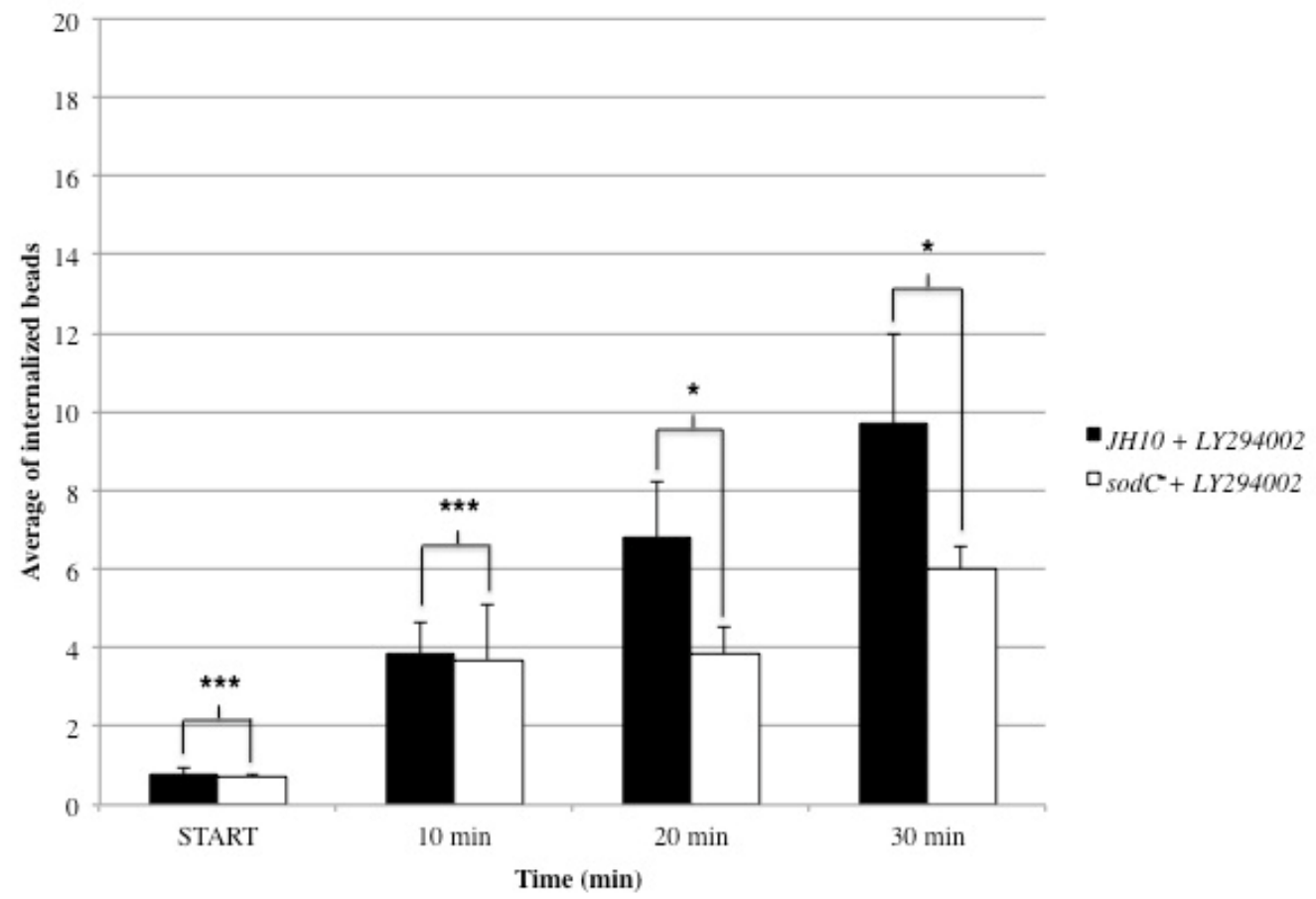

Figure 5: Particle uptake by wild type and sodC $C^{-}$Dictyostelium cells after addition of the PI3K inhibitor LY294002

The average particle uptake of three sets in both wild type and sodC- ${ }^{-}$Dictyostelium cells after the addition the PI 3-kinase inhibitor LY294002 can be seen at different feeding times. The start period represents 0-2 minutes of contact between FITC- latex beads and wild type and sodC ${ }^{-}$cells, respectively, before spinning (see Methodology). Wild type cells treated with LY294002 show significantly decreased $(\sim 40 \%)$ particle uptake over the time course while sod $C^{-}$cells generally exhibit similar level particle uptake over the assay period. $*=\mathrm{P}$ value $<0.01, * * *=\mathrm{P}$ value $>0.05$ 
Figure 6

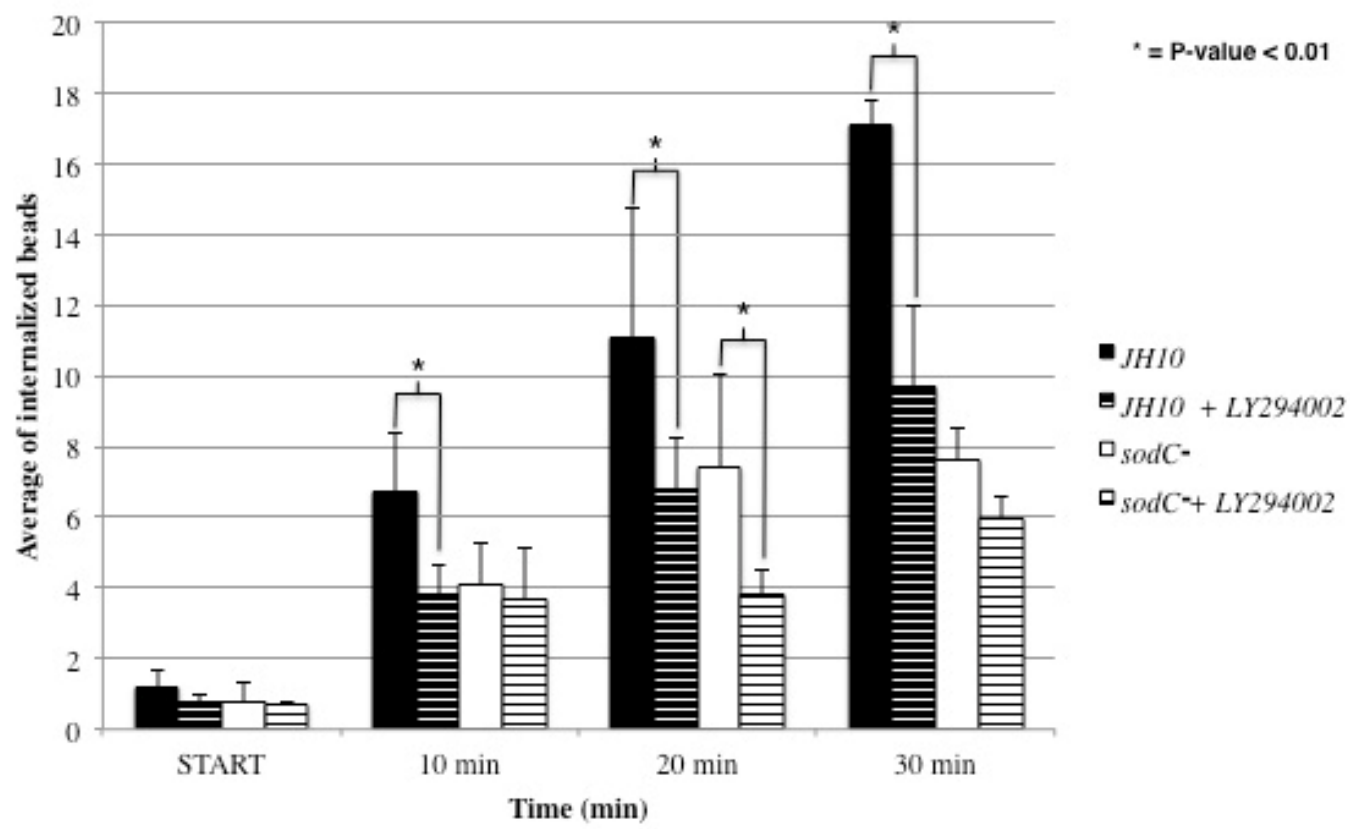

Figure 6: Comparison of particle uptake in wild type and sodC- ${ }^{-}$Dictyostelium cells before and after the addition of the PI3K inhibitor LY294002

The average particle uptake of three sets in both wild type and sodC- Dictyostelium cells before and after the addition the PI 3-kinase inhibitor LY294002 can be seen at different feeding times. The start period represents 0-2 minutes of contact between FITC- latex beads and wild type and sodC- cells, respectively, before spinning (see Methodology). Wild type cells treated with LY show significantly decreased $(\sim 30 \%)$ particle uptake over the time course when compared to wild type cells not treated with LY. sodC- cells treated with LY generally exhibit similar level particle uptake over the assay period when compared to sodC $C^{-}$cells not treated with $\mathrm{LY} .{ }^{*}=\mathrm{P}$ value $<0.01$. 


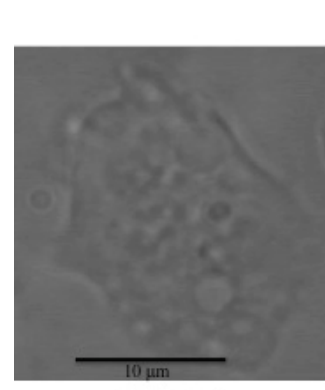

START

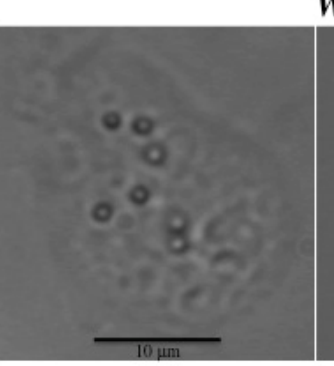

$10 \mathrm{~min}$
Wt

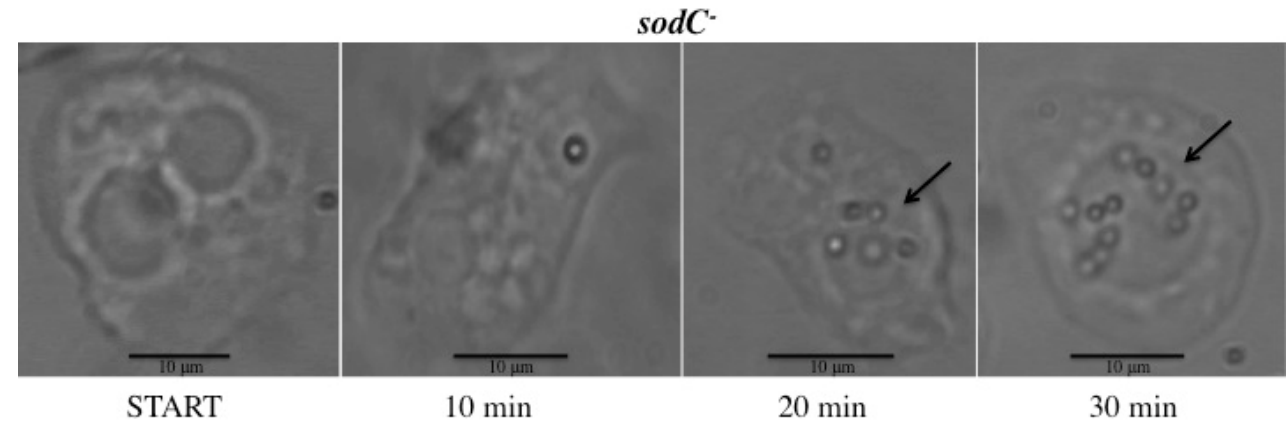

Figure 7: Particle uptake in wild type and sodC- Dictyostelium cells after addition of the PI3K inhibitor LY294002

This figure shows a decrease in particle in both wild type and sodC- cells after treatment with LY. The top pictures are representative phase contrast pictures of wild type cells chose during the different time points in the particle uptake assay. The bottom pictures are representative phase contrast pictures of sodC- cells. The start period represents $0-2$ minutes of contact between FITC- latex beads and wild type and sodC ${ }^{-}$cells before spinning (see Methodology). The arrows in the $20 \mathrm{~min}$ and $30 \mathrm{~min}$ phase contrast pictures of sodC- cells point at vacuoles where the FITC-beads are arrested in sodC- cells. 
Figure 8

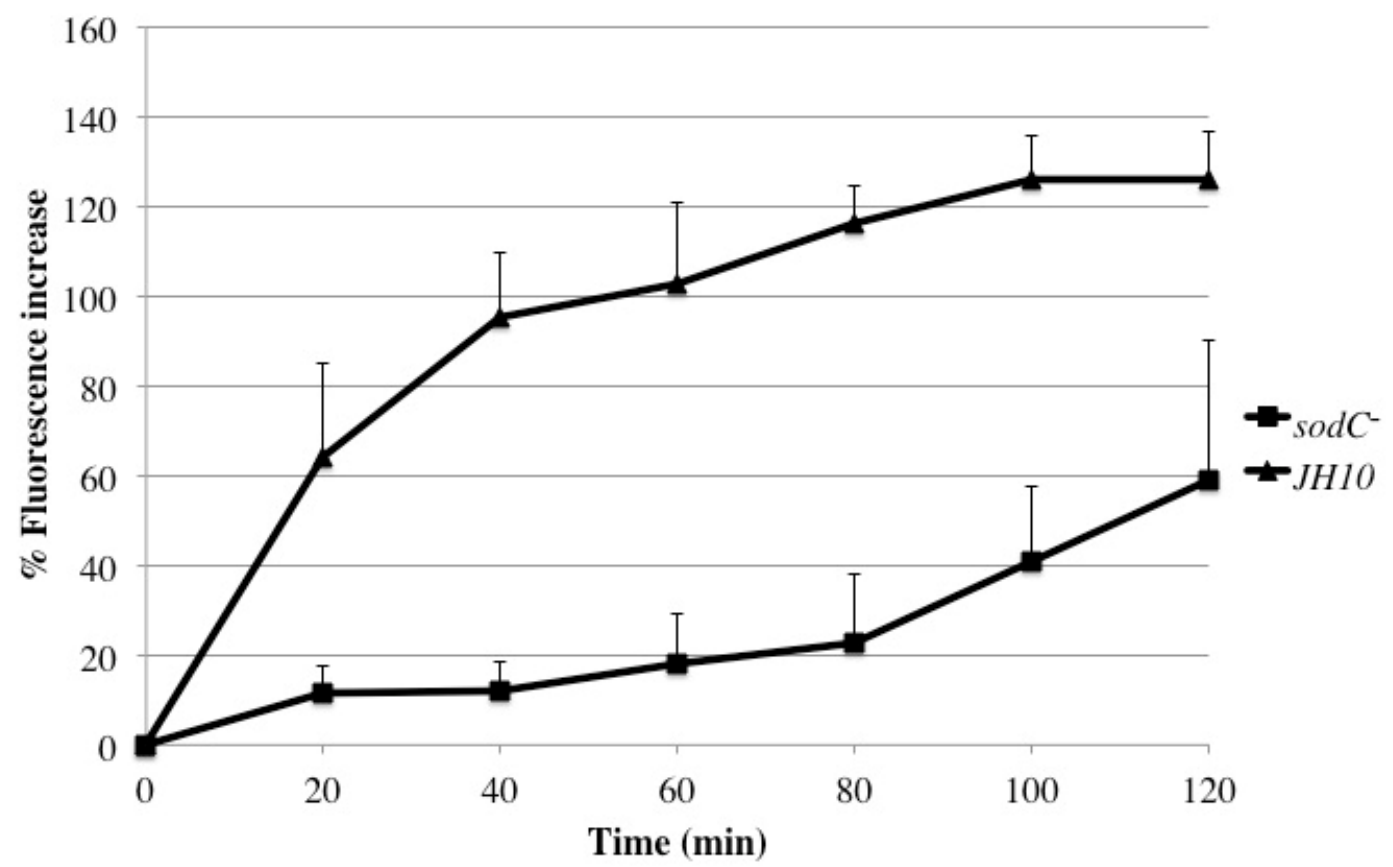

Figure 8: Exocytosis of FITC-dextran in wild type and sodC ${ }^{-}$Dictyostelium cells

Differences in fluid exocytosis can be observed between wild type and sodC ${ }^{-}$cells. Cells were incubated with fluorescent (FITC)-dextran (Mr) 70,000 up to 3 hours (see Methodology) and fluid exocytosis was subsequently measured every twenty minutes. Time zero represents the fluorescence of the extracellular medium after the initial threehour incubation. At time $0 \mathrm{~min}$, fluorescence was designated as $0 \%$ and all subsequent measurements were converted as a percent increase compared to the value at time $0 \mathrm{~min}$. Over the time course of the assay, wild type cells displayed a steady increase in fluid exocytosis that seemed to reach a plateau after 100 minutes of exocytosis. Conversely, sodC $C^{-}$cells started exocytizing significantly $\sim 25 \%$ faster after 80 minutes of exocytosis. 


\section{Chapter 5: Discussion}

Superoxide in both phagocytic and nonphagocytic cells plays a number of critical functions beyond the classical bacteriocidal function in the phagosome. NADPH oxidases (Nox), is responsible for the significant portion of cellular superoxide production, localize not only in the plasma membrane and phagosomes but also in intracellular endosomes. Mammalian Nox2, for example, exhibit plasma membrane and phagosomal localizations, upon which it mediates extracellular superoxide production. Nox1, in contrast, exhibits intracellular endosomal localization. Superoxide generation in vascular cells occurs in the early endosome and requires the expression of chloride channel 3 (CLC3), which is a broad specificity anion channel that could support superoxide transport from endosome to cytoplasm, it was suggested that Nox2-generated endosomal superoxide radicals transport to the cytoplasm through CLC3 (Miller et al., 2007; Lassegue, 2007; Brown and Griendling, 2009).

Given that superoxide radicals can be detrimental to the host, it is highly likely that cells not only tightly control the production of the superoxide, but also regulate the endosomal levels of the radical. Among the three types of Superoxide Dismutases, the extracellular superoxide dismutase, EC-SOD, is likely to play a host protective role in the

endosomes. Other SOD proteins are either mitochondrial or cytoplasmic. A recent study demonstrated that EC-SOD does indeed localize in the endosomes, while a naturally occurring genetic variant, EC-SODR213G, fails to do so (Chu et al., 2006). The goal of the study was to determine if EC-SOD localize to the nucleus, but the endosomal ECSOD proteins did not translocate to the nucleus and so the function of endosomal EC- 
SOD is not known. Dictyostelium cells also contain multiple types of SOD protein including the extracellular one, SodC (Veeranki, et al., 2008). Dictyostelium SodC localizes on the plasma membrane (Veeranki et al., 2008), but the follow up study showed that cells lacking SodC ( $\operatorname{sod} C^{-}$cells) display intracellular vesicular accumulation of superoxide radicals and a version of GFP fused SodC localized intracellular vesicular compartment (unpublished data, Kim Lab).

Earlier studies on sodC- cells disclosed its role in directional cell migration through regulating redox sensitive small GTPase RasG (Veeranki et al., 2008). Furthermore, a study showed that cells expressing constitutively activated mutant RasG(G12T) increased Cell-Substratum Adhesion, but decreased filopodia formation and phagocytosis (Chen and Katz, 2000). Consistent with the previous RasG (G12T) overexpression study, sodC- cells, which display high basal RasG activity, were significantly impaired in particle uptake. The current study, however, uncovered that not only the efficiency of particle uptake is decreased in $\operatorname{sod} C^{-}$cells, but also the fate of the internalized particles was completely derailed. Instead of joining lysosomal pathway, particles in sodC- cells efficiently recruited into aberrant vacuoles. A study in our laboratory recently determined that these vacuoles lack lysosomal markers (unpublished data, Kim lab). Apparently, particles in these non-lysosomal vacuoles have escaped from the destruction fate and would have more options of establishing their relationship with Dictyostelium cells.

To further dissect the effect of superoxide on particle uptake, wild type and sodCcells were treated with the PI3K inhibitor LY294002 that inhibits macropinocytosis but 
not phagocytosis. As described earlier, wild type cells exhibited dramatic decrease in the particle uptake upon LY294002 treatment but no such effect was observed from sodCcells treated identically, indicating that SodC is critical for proper macropinocytosis rather than phagocytosis. Considering that SodC is regulating RasG, which in turn controls PI3K activation and thus macropinocytosis, the aberrant hyperactivation of RasG in sodC cells is likely the cause for the decreased particle uptake. It is, however, puzzling that PI3K inhibition did not improve particle uptake of sodC- cells, considering that LY294002 treated sodC- cells displayed excellent chemotaxis (Veeranki et al., 2008). It is thus likely that there exist additional defects that hamper particle uptake behavior of sodC- cells.

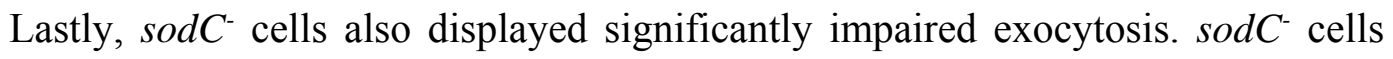
not only showed lower level of fluid phase discharge, but also severely delayed discharge. Considering that cells were saturated with 3 hour FITC-dextran feeding, a rapid initial exocytosis is expected with delayed saturating phase as cellular interior is chased with non-fluorescent media. Wild type cells exactly displayed this pattern, but sodC $C^{-}$cells were resistant for exocytosis for an hour and then showed delayed yet lower level of discharge. This is likely that the convergence of not only the particles, but also

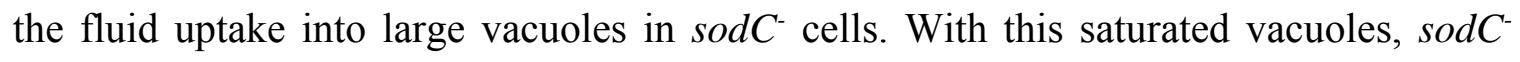
cells would experience much limited room for trafficking both particles and fluids.

This study, for the first time, demonstrated that proper metabolism of reactive oxygen species Superoxide is critical for efficient particle uptake, proper trafficking of the internalized particles, and exocytosis in Dictyostelium cells. Given that all the 
components discussed here are conserved in higher eukaryotes including human, the current study will be highly informative for other disciplines of science such as pathogenhost interaction and symbiosis.

\subsubsection{Relevance to mammalian cells}

The process of macropinocytosis has recently emerged as a major endocytic mechanism in the cell entry of animal viruses (Mercer and Helenius, 2012) and it is known that pathogens such as Legionella pneumophila increase superoxide dismutase SodA (homologous to SodC) in early endosomes and that it is able to replicate in hosts that lack coronin due to improper superoxide generation at the phagosome (Shevchuck et al., 2009). Hence this study will be highly informative for pathogen-host interaction and symbiosis.

In addition to the importance of better understanding the role of superoxide dismutase in pathogen-host interaction during the early and later steps of endocytic processes, the exocytosis of eukaryotic vesicles has recently become of upmost importance in understanding drug detoxification and other cellular responses (Tatischeff, 2013). Exosomes were originally believed to be a waste reservoir, but through different studies, the roles of exosomes have been found to include transferring immunity in blood cells, behaving as pathogenic biomarkers, and mediating intracellular communication. The study of the regulation of exosomes during exocytosis has proven to be a difficult task in human cells due to the complexity of the different cell types; hence by studying a simple model system such as Dictyostelium discoideum, whose homology to cells of the 
innate immune system makes them excellent systems to study biochemical pathways in neutrophils and macrophages, has become an ideal.

\subsection{Future perspective}

The misregulation of the macropinocytic pathway in sodC- cells is evident as the destination of the particles internalized by sod $C^{-}$cells is different than in wild type $D$. discoideum cells. Instead of the particles progressing towards the early and late endosomes, latex beads in sodC- cells end up in vacuoles (Fig. 3 and Fig.7). Because the identity of this vacuoles is not well studied, by tracking some of the regulatory proteins known to be involved in macropinocytosis we could be able to understand better this

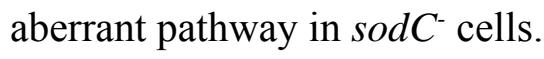

Some of the GFP tagged regulatory proteins that could be utilized are: coronin (coronin-GFP), a construct with two tandem FYVE domains (2FYVE-GFP) from an early endosome that binds PI(3)P, and active Ras protein marker (GFP-RBD). Studies have shown that coronin is enriched in the phagocytic cups that form in response to particle attachment, that it accumulates in the phagocytic cups in less than one minute after particle attachment and that it is gradually released from the cups one minute after particle engulfment (Maniak et al., 1995). Active Ras is an upstream regulator of PI3K (Sasaki et al., 2004; Cox and Der, 2003; Heo and Campbell, 2005; Veeranki et al., 2008).

One type of PI3K, Vps34, which is not activated by Ras, is responsible for most $\mathrm{PI}(3) \mathrm{P}$ generated on phagosomes (Bohdanowicz and Grinstein, 2013). In addition to the role of $\mathrm{PI}(3) \mathrm{P}$ in phagosome maturation, $\mathrm{PI}(3) \mathrm{P}$ is essential for the generation of ROS within maturing phagosomes because it recruits subunits of the NADPH oxidase complex that is 
required for phagosomes to generate superoxide (Bohdanowicz and Grinstein, 2013). By colocalization studies on coronin, the construct with the two FYVE domains, and active Ras we could be able to track the phagosomes from particle uptake to degradation or exocytosis in Dictyostelium discoideum cells lacking superoxide dismutase C and in wild type. 


\section{References}

Annesley SJ, Fisher PR (2009) Dictyostelium discoideum-a model for many reasons. Mol Cell Biochem 329: 73-91.

Bohdanomicz M, Grinstein S (2013) Role of phospholipids in endocytosis, phagocytosis, and macropinocytosis. Physiol Rev 93:69-106.

Bozzaro S, Bucci C, Steinert M (2008) Phagocytosis and host-pathogen interactions in Dictyostelium with a look at macrophages. Int Rev Cell Mol Biol 271:253-300.

Bretschneider T, Anderson K, Ecke M, Muller-Taubengerger A, Schrothdiez B, Ishikawa-Ankerhold HC, Gerisch G (2009) The three-dimensional dynamics of actin waves, a model of cytoskeletal self-organization. Biophys J 96:2888-2900.

Brooker RJ (2011) Genetics: Analysis and Principles. McGraw-Hill Higher Education $4^{\text {th }}$ ed.

Brown DI, Griendling KK (2009) Nox proteins in signal transduction. Free Radical Biology \& Medicine 47:1239-1253.

Cardelli J (2001) Phagocytosis and macropinocytosis in Dictyostelium. Phosphoinositidebased processes, biochemically distinct. Traffic 2: 311-20

Carnell M, Zech T, Calaminus SD, Seiji U, Hagedorn M, Johnston SA, May RC, Soldati T, Machesky LM, Insall RH (2011) Actin polymerization driven by WASH causes VATPase retrieval and vesicle neutralization before exocytosis. J Cell Biol. 193(5): 831839.

Charette SJ, Cosson P (2006) Exocytosis of late endosomes does not directly contribute membrane to the formation of phagocytic cups or pseudopods in Dictyostelium. FEBS Letters 580:4923-4928.

Chen CF, Katz ER (2000) Mediation of cell-substratum adhesion by RasG in Dictostelium. Journal of Biochemistry 79:139-149.

Chu Y, Piper R, Richardson S, Watanabe Y, Patel P, Heistad DD (2006) Endocytosis of extracellular superoxide dismutase into endothelial cells. Arteriosclerosis, Thrombosis, and Vascular Biology 26:1985-1990 
Chubb JR, Wilkins A, Thomas GM, Insall RH (2000) The Dictyostelium RasS protein is required for macropinocytosis, phagocytosis, and the control of cell movement. J Cell Sci 113:709-719.

Clarke M, Maddera L, Engel U, Gerisch G (2010) Retrieval of the vacuolar H+=ATPase from phagosomes revealed by live cell imaging. PlosONE 5(1): e8585

Clarke M, Kohler J, Heuser J, Gerisch G (2002). Endosome fusion and microtubulebased dynamics in the early endocytic pathway of Dictyostelium. Traffic 3: 791-800.

Cornillion S, Pech E, Benghezal M, Ravanel K, Gaynor E, Letourner F, Bruckert F, Cosson P (2000). Phg $1 \mathrm{p}$ is a nine-transmembrane protein superfamily member involved in Dictyostelium adhesion and phagocytosis. J Biol Chem 275:34287-34292.

Cornillion S, Gebbie L, Benghezal M, Nair P, Keller S, Wehrle-Haller B, Charette SJ, Bruckert F, Letourneur F, Cosson P (2006) An adhesion molecule in free-living Dictyostelium amoebae with integrin beta features. EMBO Rep 7:617-621.

Cosson P, Soldati T (2008) Eat, kill or die: when amoeba meets bacteria. Current Opinion in Microbiology 11:271-276.

Cox AD and Der CJ (2003). The dark side of Ras: regulation of apoptosis. Oncogene 22: 8999-9006.

Fey S, Stephens S, Titus MA, Chisholm RL (2002) SadA, a novel adhesion receptor in Dictyostelium. J Cell Biol 159:1109-1119.

Hacker U, Albrecht R, Maniak M (1997). Fluid-phase uptake by macropinocytosis in Dictyostelium. J Cell Sci 110: 105-112.

Heo J and Campbell SL (2005). Superoxide anion radical modulates the activity of Ras and Ras-related GTPase by a radical-based mechanism similar to that of nitric oxide. $J$ Biol Chem 280: 12438-12445.

Hoeller O, Bolourani P, Clark J, Stephens LR, Hawkins PT, Weiner OD, Weeks G, Kay RR (2013) Two distinct functions for PI3-kinases in macropinocytosis. Journal of Cell Science 126:4296-4307.

Hoeller O, Kay RR (2007). Chemotaxis in the absence of PIP3 gradients. Curr Biol. 17:813-817.

Insall R, Muller-Taubenberger A, Machesky L, Kohler J, Simmeth E, Atkinson SJ, Weber I, Gerisch G (2001). Dynamics of the Dictyostelium Arp2/3 complex in endocytosis, cytokinesis, and chemotaxis. Cell Motil Cytoskeleton 50:115-128. 
Jefferies KC, Cipriano DJ, Forgac M (2008) Function, structure and regulation of the vacuolar $\left(\mathrm{H}^{+}\right)$-ATPases. Arch Biochem. Biophys. 476:33-42.

Kim HJ, Kim CH, Ryu JH, Kim MJ, Park CY, Lee JM, Holtzman MJ, Yoon JH (2013)

Reactive oxygen species induce antiviral innate immune response through IFN- $\lambda$ regulation in human nasal epithelial cells. Cell Mol Biol 49(5):855-865.

Konzok A, Weber I, Simmeth E, Hacker U, Maniak M, Muller-Taubenberger A (1999). DAip1, a Dictyostelium homologue of the yeast actin-interacting protein 1, is involved in endocytosis, cytokinesis and motility. J Cell Biol 146: 453-464.

Koo IC, Ohol YM, Wu P, Morisaki JH, Cox JS, Brown EJ (2008) Role for lysosomal enzyme beta-hexosaminidase in the control of mycobacteria infection. Proc Natl Acad Sci USA 105:710-715.

Lassegue B (2007) How does the chloride /proton antiporter ClC-3 control NADPH oxidase? Circ Res 101:648-650.

Maniak M (2003) Fusion and fission events in the endocytic pathway of Dictyostelium. Traffic 4: $1-5$

Maniak M (2002) Conserved features of endocytosis in Dictyostelium. Int Rev Cytol 221: 257-287.

Maniak M (2001) Fluid-phase uptake and transit in axenic Dictyostelium cells. Biochim Biophys Acta. 1525(3):197-204.

Maniak M, Rauchenberger R, Albrecht R, Murphy J, Gerisch G (1995) Coronin involved in phagocytosis: dynamics of particle-induced relocalization visualized by a green fluorescent protein Tag. Cell 83:915-924

Mercer J, Helenius A (2012) Gulping rather than sipping: macropinocytosis as a way of virus entry. Current Opinion in Microbiology 15:490-499.

Miller FJ, Filali M, Huss GJ, Stanic B, Chamsedine A, Barna TJ, Lamb FS (2007) Cytokine activation of nuclear factor kappa B is vascular smooth muscle cells requires signaling endosomes containing Nox1 and ClC-3. Circ Res 101:663-671.

Peracino B, Borleis J, Jin T, Westphal M, Schwartz JM, Wu L, Bracco E, Gerisch G, Devreotes P, Bozzaro S (1998). G protein $\beta$ subunit-null mutants are impaired in phagocytosis and chemotaxis due to inappropriate regulation of the actin cytoskeleton. $J$ Cell Biol 141: 1529-1537. 
Reeves EP, Lu H, Jacobs HL, Messina CG, Bolsover S, Gabella G, Potma EO, Warley A, Roes J, Segal AW (2002) Killing activity of neutrophils is mediated through activation of proteases by $\mathrm{K}^{+}$flux. Nature 416:291-297.

Rupper A, Lee K, Knecht D, Cardelli J (2001). Sequential activities of phosphoinositide 3-kinase, PKB/Akt, and rab7 during macropinosome formation in Dictyostelium. Mol Biol Cell 12:2813-2824.

Sasaki AT, Chung C, Takeda K, Firtel RA (2004). Localized Ras signaling at the leading edge regulates PI3K, cell polarity, and directional movement. J Cell Biol 167: 505-518

Seastone DJ, Harris E, Temesvari LA, Bear JE, Saxe CL, Cardelli J (2001) The WASplike protein Scar regulates macropinocytosis, phagocytosis and endosomal membrane flow in Dictyostelium. Journal of Cell Science 114: 2673-2683

Seastone DJ, Zhang L, Buczynski G, Rebstein P, Weeks G, Spiegelman G, Cardelli J (1999) The small Mr Ras-like GTPase Rap1 and the phospholipase C pathway act to regulate phagocytosis in Dictyostelium discoideum. Mol Biol Cell 10:393-406.

Seastone DJ, Lee E, Bush J, Knecht D, Cardelli J (1998). Overexpression of a novel rho family GTPase, RacC, induces unusual actin-based structures and positively affects phagocytosis in Dictyostelium discoideum. Mol Biol Cell 9:1891-2904.

Shevchuck O, Batzilla C, Hagele S, Kusch H, Engelmann S, Hecker M, Haas A, Heuner K, Glockner G, Steinert M (2009). Proteomic analysis of Legionella-containing phagosomes isolated from Dictyostelium. International Journal of Medical Microbiology 299: 489-508.

Tatischeff I (2013) Assets of the non-pathogenic microorganism Dictyostelium discoideum as a model for the study of eukaryotic extracellular vesicles. F1000Research 2:73.

Temesvari L, Zhang L, Fodera B, Janssen KP, Scleicher M, Cardelli JA (2000) Inactivation of $1 \mathrm{mpA}$, encoding a LIMPII-related endosomal protein, suppresses the internalization and endosomal trafficking defects in profiling-null mutants. Mol Biol Cell 11:2019-2031.

Veeranki S, Kim B, Kim L (2008) The GPI-anchored superoxide dismutase SodC is essential for regulating basal Ras activity and for chemotaxis of Dictyostelium discoideum. Journal of Cell Science 121: 3099-3108.

Veltman DM, Lemieux MG, Knecht DA, Insall RH (2014). PIP3-dependant macropinocytosis is incompatible with chemotaxis. J. Cell Biol 204(4): 497-505. 
West P, Shadel GS, \& Ghosh S (2011) Mitochondria in innate immune responses. Nature Reviews Immunology 11:389-402

Wilkins A, Chubb JR, Insall RH (2000) A novel Dictyostelium RasGEF is required for normal endocytosis, cell motility and multicellular development. Curr Biol 10:14271437.

Williams RSB, Boeckeler K, Graf R, Muller-Taubenberger A, Li Z, Isberg RR, Wessels D, Soll DR, Alexander H, Alexander S (2006) Towards a molecular understanding of human diseases using Dictyostelium discoideum. Trends in Molecular Medicine 12(9). 